\title{
Telegenetics: application of a tele-education program in genetic syndromes for Brazilian students
}

\author{
Luciana Paula MAXIMINO', Mirela Machado PICOLINI-PEREIRA², José Luiz Brito de CARVALHO²
}

1- Department of Speech-Language Pathology and Audiology, Bauru School of Dentistry, University of São Paulo, Bauru, SP, Brazil.

2- Bauru School of Dentistry, University of São Paulo, Bauru, SP, Brazil.

Corresponding address: Luciana Paula Maximino - Faculdade de Odontologia de Bauru - Departamento de Fonoaudiologia - Al. Dr. Octávio Pinheiro Brisola, 9-75 - 17012-900 - Bauru - SP - Brasil - Phone: +55 1432358000 - e-mail: lumaximino@uol.com.br

Submitted: January 6, 2014 - Modification: July 1, 2014 - Accepted: July 1, 2014

\section{ABSTRACT}

W ith the high occurrence of genetic anomalies in Brazil and the manifestations of communication disorders associated with these conditions, the development of educative actions that comprise these illnesses can bring unique benefits in the identification and appropriate treatment of these clinical pictures. Objective: The aim of this study was to develop and analyze an educational program in genetic syndromes for elementary students applied in two Brazilian states, using an Interactive Tele-education model. Material and Methods: The study was carried out in 4 schools: two in the state of São Paulo, Southeast Region, Brazil, and two in the state of Amazonas, North Region, Brazil. Forty-five students, both genders, aged between 13 and 14 years, of the $9^{\text {th }}$ grade of the basic education of both public and private system, were divided into two groups: 21 of São Paulo Group (SPG) and 24 of Amazonas Group (AMG). The educational program lasted about 3 months and was divided into two stages including both classroom and distance activities on genetic syndromes. The classroom activity was carried out separately in each school, with expository lessons, graphs and audiovisual contents. In the activity at a distance the educational content was presented to students by means of the I nteractive Tele-education model. In this stage, the students had access a Cybertutor, using the Young Doctor Project methodology. In order to measure the effectiveness of the educational program, the Problem Situation Questionnaire (PSQ) and the Web Site Motivational Analysis Checklist adapted (FPM) were used. Results: The program developed was effective for knowledge acquisition in $80 \%$ of the groups. FPM showed a high satisfaction index from the participants in relation to the Interactive Tele-education, evaluating the program as "awesome course". No statistically significant differences between the groups regarding type of school or state were observed. Conclusion: Thus, the Tele-Education Program can be used as a tool for educational purposes in genetic syndromes of other populations, in several regions of Brazil.

Keywords: Telemedicine. Genetics. Distance education. Health education. Speech, language and hearing sciences.

\section{NTRODUCTI ON}

Considering the high incidence of genetic abnormalities in Brazil, 75,818 in 11,806,180 are born living ${ }^{16}$ in a vast territory of $8,547,403 \mathrm{~km}^{14}$ and a population of approximately 190 million people ${ }^{14}$, the encouragement and development of educational programs covering the topic of health promotion and disease prevention in the context of genetic syndromes is necessary.
Given this scenario, Tele-health on the side of Tele-education applies to this model of health education. Tele-health can be defined under the focus of the provision of health services at a distance using any mode of communication that allows the physical separation of the users ${ }^{5,11,15}$.

Educational programs in the use of educational resources through the use of Information and Communication Technologies (ICTs) enable the dissemination of information to a larger number of 
people, reduce the inequalities, overcome physical and geographical barriers, training and updating professional practice, the and minimize costs ${ }^{9,23,25}$.

In the area of Tele-genetics, the international literature denotes a growing advancement of studies that encompass actions and practices in Tele-health ${ }^{10,12,13,28}$ and with individuals with genetic syndromes ${ }^{4}$. Meanwhile, in the Brazilian literature, Tele-genetics is growing, with studies focused on the medical education of students ${ }^{24}$, education in genetic syndromes, and etiological and social aspects $^{21,22}$, among others.

The aim of this study was to develop and analyze an educational program in genetic syndromes for elementary students applied in two Brazilian states, using an Interactive Tele-education model.

\section{MATERI AL AND METHODS}

The study included 45 students, of both genders, aged between 13 and 14 years, divided into two groups in two Brazilian states (Figure 1). Thus, the State of São Paulo, Southeast Region, Brazil, is represented by SPG, and the State of Amazonas, North Region, Brazil by AMG.

The study was approved by the Ethics Committee of the Bauru School of Dentistry, University of São Paulo (FOB/USP) under protocol 178/2011, with all those responsible having signed an informed consent form.

\section{Education program in genetic syndromes}

The education program developed in genetic syndromes had an average duration of 4 months in each Brazilian state and consisted of 5 steps: classroom activity, activity at a distance, assessment of learning, motivational assessment and multiplication of knowledge.

\section{Classroom activity}

The classroom activity was performed in 2 meetings, each lasting an average of 4 hours.

The educational content of this stage was designed with the Microsoft ${ }^{\circledR}$ Office PowerPoint in presentation format exhibited with the theme of genetic syndromes. The main topic discussed at these meetings included an introduction to basic genetic and etiologic implications.

The graphical content (illustrative images) and media (videos) used in this phase were granted by the collaboration of the FOB/USP Speech-Language Pathology and Audiology Clinic and the Hospital for
Rehabilitation of Craniofacial Anomalies, University of São Paulo (HRAC/USP).

\section{Activity at a distance}

The educational content of the activity at a distance was available on the Young Doctor Project interactive website (http://www. projetojovemdoutor.org.br).

The virtual learning environment (VLE) used in this step was a Cybertutor on genetic syndromes. The Cybertutor or electronic tutor on the web enables student learning through the Internet, in an interactive format, allowing verification of performance by both the students themselves as well as the tutors. It also features interactive resources, and a forum and discussion list that ensures a greater proximity of the tutor program with the participants.

\section{Assessment of learning}

The instrument entitled "Problem Situation Questionnaire" (PSQ) ${ }^{20}$ was used to measure the theoretical knowledge acquired by the student.

The questionnaire was administered at two different times, pre and post-test, ie before and after the educational program. The PSQ has 5 multiple choice problem-solving situations, each with 5 alternatives, of which only one is correct. The number of correct answers in the questionnaire can vary, with a minimum score of 0 and a maximum of 5 .

\section{Motivational assessment}

Web Site Motivational Analysis Checklist adapted $(\text { FPM })^{19}$ was used to subjectively evaluate the motivational aspects of the educational program. It is composed of 32 statements grouped into four dimensions: "Stimulating", "Meaningful", "Organized" and "Easy-to-Use".

This instrument was constructed to evaluate the website, and after an adjustment, became applicable to the subjective evaluation of the motivational courses and programs involving education at a distance.

\section{Multiplication of knowledge}

At this stage the participants of the educational program should multiply the acquired knowledge for the students of the school, teachers and the general community. To provide greater involvement and student motivation, we decided to adopt this step to the Young Doctor Project methodology.

\begin{tabular}{|c|c|c|c|}
\hline Group & Number of participants & Public School & Private School \\
\hline SPG & 21 & 9 & 12 \\
\hline AMG & 24 & 12 & 12 \\
\hline
\end{tabular}

Figure 1- Sample distribution according to group and type of school. SPG=São Paulo group; AMG=Amazonas group 
The Young Doctor Project, contrary to what the name suggests, does not mean the young doctor, but the young with knowledge in a specific topic. These design features of Tele-health, Interactive Tele-education and the Virtual Human Project ${ }^{23}$ are used for the purpose of encouraging students to undertake cooperative work acting in the promotion of health and change of habits, thus improving the quality of life in communities in need.

\section{Analysis of results}

The statistical analysis of the assessment instruments considered the mean, median and standard deviation. The comparison between groups and variables was carried out by the unpaired Student's t-test. In the comparison considering the same group, the paired t-test was utilized. All tests were performed with a significance level of $5 \%$. For statistical analyses was utilized the software Sigmaplot 12.0.

\section{RESULTS}

The education program in genetic syndromes was developed by two graduate students and a professor from FOB/USP. In the state of São Paulo, city of Bauru (SP) and the state of Amazonas, city of Manaus (AM), the program had an average duration of 4 months, beginning in September and ending in December 2010 and 2011, respectively.

We decided to choose two geographically distant states with cultural, social and economic differences, in order to verify the effectiveness of the program independent of these variables.
Thus, the study was conducted in 4 schools, 2 in the state of São Paulo and 2 in the state of Amazonas. It is noteworthy that in each state one school was public and the other was private.

\section{Classroom activity}

All students, ie $100 \%$ of the participants of the SPG and the AMG attended the classroom activities.

The class exhibition elaborated with the genetic syndrome themes included the spontaneous voluntary participation of the students.

The student attendance and involvement at this stage showed a satisfactory performance of the participants in classroom activities.

\section{Activity at a distance}

Before performing this step a VLE, Cybertutor had been developed for genetic syndromes, specifically for elementary school students ${ }^{21}$.

Access to the Cybertutor was conducted at the Young Doctor Project website (http://www. projetojovemdoutor.com.br) with the student ID and password. This step had an average duration of one month. In this process the students directed their own learning, accessing as needed.

The Cybertutor consists of 52 screens with images, text and videos. In Part I, there was an introduction to the basic concepts of genetics and genetic syndromes and in Part II, the content includes aspects of health education, prevention and laws governing inclusive education.

A mailing list was also used to keep the interaction between the tutor and the students. Note that this list was not considered a mandatory

Table 1- Mean and standard deviation of the Problem Situation Questionnaire, under pre- and post-test conditions, according to group and type of school

\begin{tabular}{cccccc}
\hline Groups & Condition & \multicolumn{2}{c}{ Private School } & \multicolumn{2}{c}{$\begin{array}{c}\text { Public School } \\
\text { PSQ }\end{array}$} \\
& & Mean & SD & Mean & SD \\
\hline SPG & Pre-test & 2.50 & 1.78 & 2.22 & 1.79 \\
& Post-test & 4.08 & 0.90 & 4.00 & 1.32 \\
& Pre-test & 2.67 & 1.07 & 3.33 & 1.30 \\
AMG & Post-test & 4.50 & 0.67 & 4.75 & 0.45 \\
\hline
\end{tabular}

PSQ=Problem Situation Questionnaire; SPG=São Paulo Group; AMG=Amazonas Group; SD=Standard Deviation

Table 2- Mean and standard deviation of the SPG and the AMG in the Problem Situation Questionnaire, under pre- and post-test conditions

\begin{tabular}{ccccccc}
\hline Questionnaire & Condition & \multicolumn{2}{c}{ SPG } & \multicolumn{2}{c}{ AMG } & Value $\mathbf{p}$ \\
& & Mean & SD & Mean & SD & \\
\hline QSP & Pre & 2.38 & 1.75 & 3.00 & 1.22 & 0.17 \\
& Post & 4.05 & 1.07 & 4.63 & 0.58 & 0.027 \\
\hline
\end{tabular}

PSQ=Problem Situation Questionnaire; SPG=São Paulo Group; AMG=Amazonas Group; SD=Standard Deviation 
activity, so participants could access the program at any time.

Cybertutor also allowed the performance verification and participant access. All students $(100 \%)$ accessed the Cybertutor and carried out the proposed activities on the website.

\section{Evaluation of learning}

The PSQ was an assessment tool of paramount importance to justify the effectiveness of the program.

With regards to the theoretical knowledge assessed by the PSQ of students from private and public schools of the SPG and AMG, an improved performance in the post-test evaluation was observed with no statistical significant difference between the performance of students from the type of school, public or private, using the unpaired Student t Test (Table 1).

In Table 2, schools showing a better performance for the AMG were grouped both in the pre and posttest. The performance of students from both the
SPG as well as the AMG was significantly higher in the post-test compared with the pre-test $(p=0.027)$ using the unpaired Student T-test.

This finding confirms that there was an increase in the theoretical learning acquired in the theme of genetic syndromes in both groups after the program.

\section{Motivational evaluation}

The FPM measured the motivational aspects in relation to the distance activity, ie using Cybertutor while using the virtual learning environment. The FPM was answered by $100 \%$ of the sample. Students took an average of 15 minutes to answer this instrument.

The dimension most reported by the SPG and AMG students was organized and less evident and easy-to-use by the SPG and meaningful for the AMG (Table 3).

In the analysis considering the variable type of school (Table 4), it can be noted that there was a statistically significant difference in the size of the

Table 3- Mean, median, minimum, maximum and standard deviation (SD) values assessed by the adapted Web Site Motivational Analysis Checklist (FPM) for the SPG and AMG

\begin{tabular}{ccccccc}
\hline & Dimension & Mean & Median & Minimum & Maximum & SD \\
\hline \multirow{2}{*}{ SPG } & Stimulating & 18.9 & 19 & 13 & 24 & 2.96 \\
& Meaningful & 19.29 & 18 & 16 & 24 & 2.41 \\
& Organized & 21.1 & 22 & 16 & 24 & 2.14 \\
& Easy-to-use & 18.48 & 19 & 12 & 23 & 3.49 \\
& Stimulating & 21.29 & 21 & 17 & 28 & 2.58 \\
& Meaningful & 19.04 & 19.5 & 14 & 23 & 2.35 \\
& Organized & 22.46 & 23 & 20 & 24 & 1.5 \\
& Easy-to-use & 21.17 & 21.5 & 16 & 24 & 2.41 \\
\hline
\end{tabular}

SPG=São Paulo Group; $\mathrm{AMG}=\mathrm{Amazonas}$ Group; $\mathrm{SD}=$ Standard Deviation

Table 4- Mean and standard deviation of the assessed dimensions of the adapted Web Site Motivational Analysis Checklist (FPM) in the SPG and AMG, according to type of school

\begin{tabular}{|c|c|c|c|c|c|c|}
\hline \multirow[t]{2}{*}{ Groups } & \multirow[t]{2}{*}{ Dimension } & \multicolumn{2}{|c|}{$\begin{array}{c}\text { Private School } \\
\text { FPM }\end{array}$} & \multicolumn{2}{|c|}{$\begin{array}{c}\text { Public School } \\
\text { FPM }\end{array}$} & \multirow[t]{2}{*}{ Value $p$} \\
\hline & & Mean & SD & Mean & SD & \\
\hline \multirow[t]{4}{*}{ SPG } & Stimulating & 19.50 & 2.75 & 18.11 & 3.22 & 0.300 \\
\hline & Meaningful & 19.17 & 2.67 & 19.44 & 2.24 & 0.801 \\
\hline & Organized & 21.58 & 1.73 & 20.44 & 2.55 & 0.237 \\
\hline & Easy-to-use & 20.00 & 2.59 & 16.44 & 3.61 & 0.016 \\
\hline \multirow{4}{*}{ AMG } & Stimulating & 21.33 & 2.35 & 21.25 & 2.90 & 0.939 \\
\hline & Meaningful & 19.92 & 2.02 & 18.17 & 2.41 & 0.067 \\
\hline & Organized & 23.08 & 1.16 & 21.83 & 1.59 & 0.039 \\
\hline & Easy-to-use & 21.83 & 1.95 & 20.50 & 2.71 & 0.181 \\
\hline
\end{tabular}

SPG=São Paulo Group; $\mathrm{AMG=Amazonas} \mathrm{Group;} \mathrm{SD}=$ Standard Deviation 


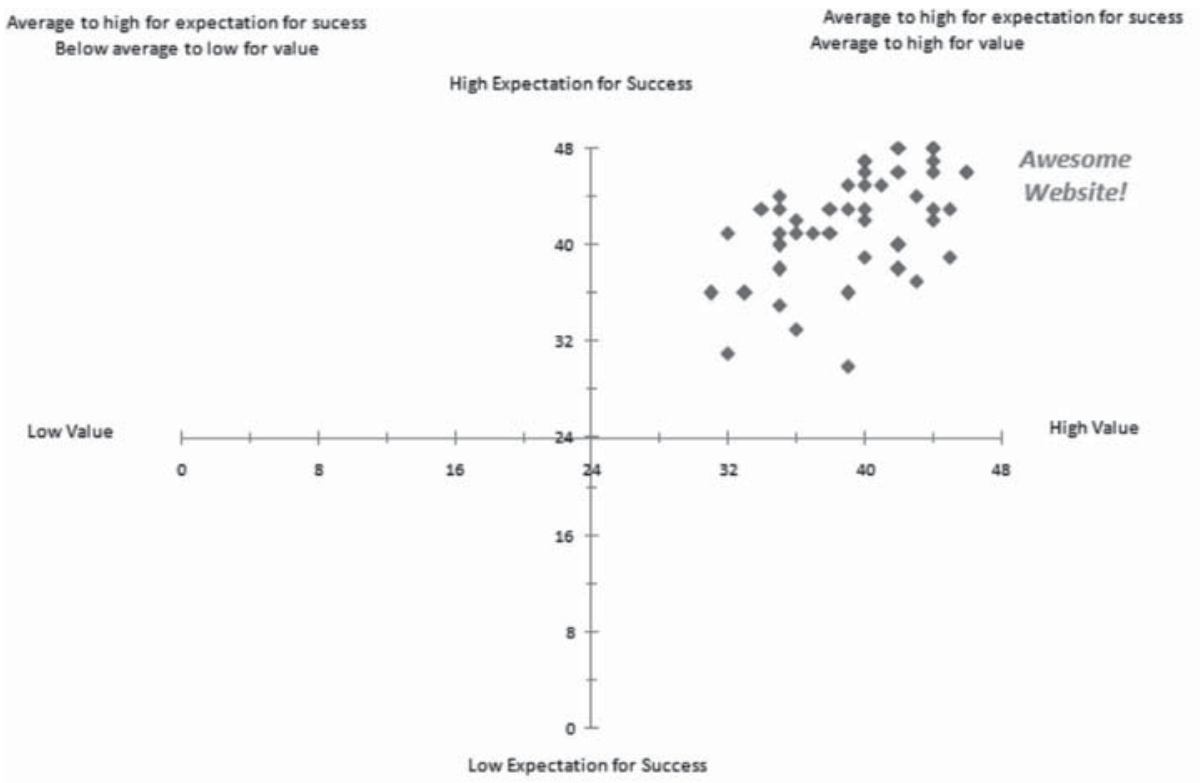

Below average to low for expectation for suces: Below average to low for value

Below average to low for expectation for sucess Average to high for value

Figure 2- Training program in genetic syndromes evaluation according to the participants of both groups

easy-to-use for the SPG $(p=0.016)$ and organized for the AMG $(p=0.039)$ according to the unpaired Student T-test.

Following the findings and recommendations of the FPM, a Cartesian projection was performed that reflects the expectation for success and value of the developed educational program (Figure 2).

According to the Cartesian projection, $100 \%$ of the participants in the SPG and AMG considered the program as "awesome course". This projection permitted the analysis that noted that the program of motivational point of view of elementary school students evaluated in this study was of high index approval, which gives objective effectiveness of the proposed material.

\section{Multiplication of knowledge}

Following the methodology of the Young Doctor Project, after completing the steps of the program, the participants were titled "Young Doctors" and multiplied the knowledge gained.

The multiplication or dissemination of knowledge was the performance of all participants as multipliers, transmitting information to other school students, teachers, staff and the community. Students received a jacket with the symbol of the Young Doctor Project and a certificate of participation.

\section{DISCUSSION}

The present study has developed an educational program with genetic syndromes having elementary school students as a target audience, using resources mediated by interactive Tele-education.
Some studies show that early incorporation of healthy habits can generate behavior changes, therefore, it should be encouraged by educational programs designed for children and adolescentes ${ }^{3,6}$.

The proposed program was divided into five phases: classroom activities, distance activities, assessment of learning, assessment motivational and multiplication of knowledge. Tele-education requires a pedagogy that will attract not only the technical approach, but it also has a concern with relationships and methodological teachings ${ }^{26}$.

The classroom activity was the first step of the program. Classroom activities with lectures, videos, images and interaction with the tutor are key factors to the success of an educational program?

Distance activities using interactive Teleeducation was the second step. Interactive Teleeducation is the optimization of technological resources and education designed to foster interactivity and maintain the interest of the student ${ }^{1}$. The educational material used in this step was a Cybertutor in thematic genetic syndromes ${ }^{21}$. The Cybertutor permitted the fragmentation of educational content on different accessible screens. Being an electronic tutor available on the Internet, access times were flexible, depending on time availability and student interest. Another advantage was the ability to access as often as was necessary.

The Cybertutor, while being an interactive virtual learning environment, was also used in other studies, verifying that it proves to be an excellent option for acquiring knowledge 2,3,6,8,18.

The assessment of learning, part of theoretical knowledge, was measured in the pre and post-test, with the findings of the PSQ. The data in Tables 1 and 
2 demonstrate that both the SPG and AMG groups obtained better results in the evaluation after the test. The problem-based learning lead to breaks with the traditional way of teaching and learning, stimulating students' participative management and reorganization of the theory/practice. Pedagogical experiences based on problem-based learning and/ or problematization may represent an innovative movement in the context of education in healthcare, fostering breaks and broader movements ${ }^{17}$.

The motivational evaluation of the program was performed through the FPM. In the SPG, there was a statistically significant difference between the type of school, regarding the "easy-to-use" dimension ( $p$ 0.016 ), probably demonstrating a greater difficulty in the use of the tool by public school students compared with private. In the AMG, the "organized" dimension was significantly higher than the other dimensions when comparing all the students, considering the school type ( $p$ 0.039) (Table 4).

The findings of this study corroborate the consulted literature ${ }^{18,19,22}$ also revealing that the FPM is an instrument of high validity for measuring the motivational aspect of distance learning courses. A website with high quality is one that contains motivational characteristics that motivate participants to visit, explore and come back to it.

Upon completion of the "Young Doctors" steps, the knowledge acquired in their respective schools was multiplied. The activities of health education should involve not only students, but the school as a whole, aiming to build healthy environments and changing the behavior of students of the community ${ }^{27}$.

The Young Doctor Project poses for elementary students an opportunity to exercise citizenship and scientific initiation with a practical application of the knowledge gained. This strategy can also be observed in other studies 3,6 , being performed in the most diverse thematics, assuming that one of the most effective ways to promote health in a community is through education.

\section{CONCLUSI ONS}

We developed an educational program in genetic syndromes for elementary students, using Interactive Tele-education. The application of this model with classroom and distance activities proved to be an effective program of health education for achieving high motivational satisfaction for the proposed population. There were no statistically significant differences between the groups regarding the type of school public or private or the evaluated Brazilian state, another finding that reinforces that this tool could be used for training in genetic syndromes for other populations and other regions of the country.

\section{REFERENCES}

1- Araújo ES, Alvarenga KF, Urnau D, Pagnossin DF, Wen CL. Community health worker training for infant hearing health: effectiveness of distance learning. Int J Audiol. 2013;52(9):63641.

2- Blasca WQ, Maximino LP, Galdino DG, Campos K, Picolini MM. New educational Technologies in Audiology teaching. Rev CEFAC. 2010; 12(6): 1017-24.

3- Blasca WQ, Picolini MM, Silva AS, Campos K, Pinto GF, Brasolotto $A G$, et al. Young Doctor Bauru Project: training of high school students in hearing health. Rev CEFAC. 2013; 15(6): 1407-17.

4- Cady R, Finkelstein S, Kelly A. A telehealth nursing intervention reduces hospitalizations in children with complex health conditions. J Telemed Telecare. 2009; 15(6):317-20.

5- Chumbler NR, Haggstrom D, Saleem JJ. Implementation of health information technology in Veterans Health Administration to support transformational change: telehealth and personal health records. Med Care. 2011;49(S)36-42.

6- Corrêa CC, Martins A, Fanton CS, Silva AS, Barros GT, Wen CL, et al. Activities of interactive teleducation in vocal health based on the Young doctor dynamics. Distúrb Comun. 2012;24(3):359-68. 7- De J ong N, Verstegen DML, Tan FES, O'Connor SJ. A comparison of classroom and online asynchronous problem-based learning for students undertaking statistics training as part of a Public Health Masters degree. Adv Health Sci Educ Theory Pract. 2013; 18(2): 245-64

8- Eskenazi ES, Martins MA, Ferreira M J r. Oral health promotion through an online training program for medical students. J Dent Educ. $2011 ; 75(5): 672-8$.

9- Hanson D, Calhoun J, Smith D. Changes in provider attitudes toward telemedicine. Telemed J E Health. 2009; 15(1):39-43.

10- Hawkins AK, Hayden MR. A grand challenge: providing benefits of clinical genetics to those in need. Genet Med. 2011; 13(3): 197200.

11- Head BA, Keeney C, Studts J L, Khayat M, Bumpous J, Pfeifer M. Feasibility and acceptance of a telehealth intervention to promote symptom management during treatment for head and neck cancer. J Support Oncol. 2011;9(1):e1-e11.

12- Hilgart JS, Hayward JA, Coles B, Iredale R. Telegenetics: a systematic review of telemedicine in genetics services. Genet Med. 2012; 14(9): 765-76.

13- Hopper B, Buckman M, Edwards M. Evaluation of satisfaction of parents with the use of videoconferencing for a pediatric genetic consultation. Twin Res Hum Genet. 2011; 14(4): 343-6.

14- Instituto Brasileiro de Geografia e Estatística. Censo Demográfico 2010. [homepage]. [cited 2011 May 28]. Available from: http://www.ibge.gov.br/home/estatistica/populacao/ censo2010/tabelas_pdf/Brasil_tab_1_15.pdf.

15- Lee D, Helal S, Anton S, De Deugd S, Smith A. Participatory and persuasive telehealth. Gerontology. 2012;58(3):269-81.

16- Ministério da Saúde. Departamento de Informática do SUS. 2011. [Homepage]. [cited 2011 July 18]. Available from: http:// tabnet.datasus.gov. br/cgi/tabcgi.exe?sinasc/cnv/nvuf. def.

17- Mitre SM, Siqueira-Batista R, Girardi-de-Mendonça J M, MoraisPinto NM, Meirelles CAB, Pinto-Porto $C$, et al. Active teachinglearning methodologies in health education: current debates. Ciênc Saúde Coletiva. 2008; 13(2): 2133-44.

18- Paixão MP, Miot HA, Souza PE, Haddad AE, Wen CL. A university extension course in leprosy: telemedicine in the Amazon for primary healthcare. J Telemed Telecare. 2009; 15(2):64-7.

19- Paixão MP, Miot HA, Wen CL. Tele-education on leprosy: evaluation of an educational strategy. Telemed J E Health. 2009; 15(6): 552-9.

20- Picolini MM. Teleducação interativa na capacitação de estudantes do ensino fundamental em síndromes genéticas [Dissertation]. Bauru: Universidade de São Paulo, Faculdade de Odontologia de Bauru; 2011 [cited 2014 Jun 24]. Available from: http://www.teses. usp.br/teses/disponiveis/25/25143/tde06122011-092357/pt-br.php. 
21- Picolini MM, Blasca WQ, Richieri-Costa A, Maximino LP. The development of a virtual learning environment in genetic syndromes. Rev CEFAC. 2013; 15(2):382-90.

22- Picolini MM, Maximino LP. Education program on genetic syndromes: motivational evaluation of an e-learning material. Rev CEFAC. 2014; 16(1):252-9.

23- Silva AS, Rizzante FA, Picolini MM, Campos K, Corrêa CC, Franco EC, et al. Bauru School of Dentistry Tele-Health League: an educational strategy applied to research, teaching and extension among applications in tele-health. J Appl Oral Sci. 2011; 19(6): 599-603.

24- Silva JM, Canedo RV, Abrantes TA, Santos RT, Souza RA, Utagawa CY. Quiz: um questionário eletrônico para autoavaliação e aprendizagem em genética e biologia molecular. Rev Bras Educ Med. 2010; 34(4):607-14.
25- Spinardi-Panes AC, Lopes-Herrera SA, Maximino LP. Telehealth in Speech, Language and Hearing Sciences: ethical and legal issues. Rev CEFAC. 2013; 15(4): 1040-3.

26- Strachan M, Gros DF, Yuen E, Ruggiero KJ, Foa EB, Acierno R. Home-based telehealth to deliver evidence-based psychotherapy in veterans with PTSD. Contemp Clin Trials. 2012;33(2):402-9.

27- Vieira PC, Aerts DRGC, Freddo SL, Bittencourt A, Monteiro L. Alcohol, tobacco, and other drug use by teenage students in a city in Southern Brazil. Cad Saúde Pública. 2008; 24(11):2487-98. 28- Zilliacus E, Meiser B, Lobb E, Dudding TE, Barlow-Stewart K, Tucker K. The virtual consultation: practitioners' experiences of genetic counseling by videoconferencing in Australia. Telemed J E Health. 2010; 16(3): 350-7. 